\title{
Aulas de História e os direitos das crianças e dos adolescentes: entre possibilidades e desafios
}

Classes of History and the Rights of Children and Adolescents: Between Possibilities and Challenges

Humberto da Silva Miranda*

\section{RESUMO}

$\mathrm{O}$ que faz uma criança ou um adolescente se tornar "sujeito de direitos"? Qual a relação do Ensino de História com os direitos humanos desses agentes sociais? Com base nessas perguntas, pretende-se problematizar a relação do saber histórico escolar com os direitos humanos de crianças e adolescentes, buscando questionar as possibilidades e os desafios vivenciados nas aulas de história frente às novas formas de entender as culturas infantis. A partir da promulgação do Estatuto da Criança e do Adolescente, a sociedade brasileira firmou um novo compromisso político com a forma de pensar as infâncias, o qual deve ser vivenciado nos espaços sociais onde esses meninos e meninas circulam. O Ensino de História se relaciona diretamente com essa questão, e sua prática nos permite efetivar o princípio reconhecido pelo Estatuto de conceber esses agentes sociais como "sujeitos de direitos".

Palavras-chave: história; infância; ensino.

\section{Abstract}

What makes a child or adolescent become a "subject of rights"? What is the relation of History Teaching with the human rights of these social agents? Based on these questions, we intend to problematize the relationship between the school's historical knowledge and the human rights of children and adolescents, trying to problematize the possibilities and the challenges experienced in history classes in the face of new ways of understanding children's cultures. Since the enactment of the Statute of the Child and the Adolescent, Brazilian society has established a new political commitment with the way of thinking about childhood, and this commitment should be experienced in the social spaces where boys and girls circulate. The History Teaching is directly related to this question, and from its practice we can accomplish the principle recognized by the Statute to conceive these social agents as "subjects of rights".

Keywords: History; childhood; teaching.

* Universidade Federal Rural de Pernambuco (UFRPE). Recife, PE, Brasil. humbertoufrpe@ gmail.com 
O que dizem crianças e adolescentes sobre as aulas de História? Como produzem conexões entre o saber histórico escolar e os direitos humanos? O que falam sobre os problemas sociais vivenciados nas suas famílias e comunidades? Essas são indagações que nos levam a pensar o espaço das aulas de História como campo de possibilidades e desafios para a garantia dos direitos de meninos e meninas, para que pensem, sintam e falem sobre si e sobre as questões que fazem parte do mundo que os norteia.

Nos dias de hoje, a sociedade brasileira vem promovendo debates efervescentes sobre os direitos humanos de crianças e adolescentes. Muitas dessas discussões vêm acompanhadas de questionamentos que colocam em xeque direitos já reconhecidos no universo legal, como o Estatuto da Criança e do Adolescente. A Redução da Maioridade Penal, por exemplo, entre outros temas conservadores, está sendo discutida por setores da sociedade brasileira. ${ }^{1}$ Essa pauta vem ganhando destaque na grande imprensa e nas redes sociais, e seguramente entra pelo portão da escola, ultrapassa os corredores e chega às salas de aula, muitas vezes sem pedir licença.

Mas o que crianças e adolescentes pensam sobre a Redução da Maioridade Penal? Como as aulas de História promovem o debate sobre esse tema, oportunizando o direito de meninos e meninas discutirem sobre as questões que impactam diretamente suas vidas? Convencionalmente, o tema da Redução da Maioridade vem sendo discutido por conselheiros tutelares, jornalistas, políticos, assistentes sociais, juízes e educadores, ou seja, por adultos, que debatem e planejam formas de governamentalidade sobre a vida de meninos e de meninas sem promover, na maioria das vezes, a participação cidadã de crianças e adolescentes no processo de decisão.

Penso que as aulas de História podem dar conta de uma questão fundamental: fazer valer o direito de crianças e adolescentes de pensar, sentir e dizer o que veem, o que planejam e o que decidem sobre si mesmos. Tal como afirmam os novos estudos sociais de crianças e adolescentes - refiro-me à sociologia da infância, à história das crianças e à antropologia da criança -, as infâncias não podem ser concebidas como a fase daqueles "que não falam", mas daqueles que constroem suas falas.

Nesse sentido, o presente artigo tem o objetivo de problematizar a relação entre direitos da criança e do adolescente e o Ensino de História, sem a pretensão de responder a todas as perguntas lançadas no início do texto, nem 
tampouco produzir "receitas de como fazer". Este trabalho busca, portanto, apresentar reflexões sobre os desafios de (re)pensar as aulas de História e sua relação com os direitos de crianças e adolescentes, com base no resultado de pesquisas no campo da História das Infâncias e do Ensino de História e nas minhas atividades de extensão universitária na área dos direitos de crianças e adolescentes.

Entendendo a temática dos direitos de crianças e adolescentes com base no reconhecimento desses agentes como "sujeitos de direitos" (conforme sinalizam os novos estudos sociais das infâncias e como preconiza o Estatuto da Criança e do Adolescente), procurei, inicialmente, debater como se construiu historicamente o reconhecimento da criança e do adolescente como "sujeitos de direitos" no Brasil, buscando problematizar as legislações vigentes e as práticas culturais marcadas pelas relações de controle e de disciplinamento. Em seguida, lancei-me à construção de conexões entre as aulas de História e as novas formas de pensar os direitos de crianças e adolescentes, à procura do amadurecimento de reflexões sobre o cotidiano das aulas de História.

\section{DE MENORES A SUJEITOS DE DIREITOS: (RE)CONHECENDO CRIANÇAS E ADOLESCENTES}

Vivenciar as aulas de História a partir de uma prática pedagógica pautada na educação em direitos humanos é possibilitar que crianças e adolescentes falem sobre si e acerca dos problemas sociais e políticos que afetam diretamente o seu cotidiano. Conforme estabelecem as Diretrizes Curriculares para a Educação Básica (Brasil, 2013), aprender História é necessário para que crianças e adolescentes possam intervir no mundo e se tornem sujeitos históricos. Mas como as pessoas se tornam sujeitos históricos?

Essa pergunta me fez recorrer a uma das preocupações centrais de Michel Foucault (1995), que consistia nesta questão: "como os seres humanos tornaram-se sujeitos?”. Para o filósofo francês, o sujeito humano é constituído a partir das relações de poder e de saber, é fabricado a partir das correlações de forças que desafiam as tensões entre as práticas de subjetivação e de objetivação das pessoas, ou seja, que as concebem como objetos.

De acordo com os estudos de Cesar Candiotto (2016, p.35), com base no pensamento de Foucault "a constituição ética do sujeito é proposta a partir do 
embate e a provocação recíproca entre as forças do desejo e as práticas de liberdade". Nesse sentido, o processo de constituição do sujeito - do "governo de si”, da emancipação e da liberdade - desafia-se nos processos de normalização, nas técnicas disciplinares, nas regras e nas relações de poder-saber.

Considerando-se essa reflexão, é possível afirmar que há variadas formas de pensar as infâncias, e tais concepções fundamentaram práticas sociais, políticas assistenciais, normativas jurídicas e pedagogias. O processo de subjetivação da infância, do sentimento de que existe um mundo particular chamado infância, é uma "fabricação" da Modernidade, como afirmou Philippe Ariès (1981). A historiografia contemporânea sinaliza que, no Brasil, as primeiras leis voltadas para crianças e adolescentes não as concebiam como "sujeitos de direitos", mas como objetos dos interesses econômicos, políticos e sociais dos adultos.

A primeira legislação voltada exclusivamente para crianças e adolescentes foi chamada de Código de Menores e tinha como objetivo vigiar e punir meninos e meninas que desafiassem as normas impostas. Promulgado em 1927, o Código reproduzia, a partir da lógica punitiva e assistencialista, um conjunto de regulações sobre crianças pobres e suas famílias. Desse Código em diante, a sociedade passou a identificar e classificar crianças e adolescentes que viviam em diferentes cenários de vulnerabilidade como "menores", ou seja, "menores carentes", "menores abandonados", "menores delinquentes" (Vianna, 1999).

O Código de Menores foi um dispositivo legal produzido para os filhos do abandono, para meninos e meninas que experimentaram as mais diferentes formas de violência nas ruas, nas instituições assistenciais ou nos espaços de confinamento. Uma lei voltada para os filhos dos trabalhadores que viviam em condição de pobreza, para meninos e meninas sem família que representavam o "perigo social" ou que "estavam em perigo de tornar-se" uma ameaça para a sociedade.

Considero que essa lei não ficou só no papel. Ela fez produzir no Brasil o que costumo chamar de cultura menorista, ou seja, um conjunto de ações baseadas nos princípios da vigilância e da punição de crianças e adolescentes que passavam a ser categorizados como menores, negando-lhes a condição de sujeito e tornando-os objetos do poder de adultos. A prática é fortemente marcada pela classificação dos meninos e das meninas, adjetivando-os como "menores" que vivenciam "situações de irregularidade" diante do Estado punitivista (Miranda, 2014). 
A cultura menorista não era praticada apenas por aqueles que seguiam o Código de Menores, os juízes ou profissionais que atuavam no Sistema de Justiça e de Segurança, mas também por diferentes pessoas que atuavam no campo da saúde, da assistência social e da educação. Nas regulações fabricadas por nossa sociedade disciplinar e de controle.

Percebo ainda que, além de estar presente nas diferentes ações punitivas praticadas contra nossos adolescentes que cumprem medidas socioeducativas, o menorismo permeia as tentativas de objetivação de meninos e meninas nos espaços formativos (escola e sala de aula, família e comunidade). O menorismo encontra-se nas práticas autoritárias que não permitem a organização política de crianças e adolescentes nas escolas, como grêmios e diretórios; nas imposições produzidas no cotidiano familiar ou comunitário; nas diferentes formas de negar a participação cidadã de meninos e meninas.

A historiografia da infância e da juventude sinaliza que, ao longo do século XX, muitas propostas políticas colocaram o tema da assistência aos meninos e meninas no centro do debate. Tais estudos afirmam que a lógica punitivista estabelecida pelo Código de Menores foi teoricamente questionada com base nos movimentos em defesa dos direitos humanos, vivenciado a partir do final da década de 1970. À luz da lei, no Brasil, a primeira legislação que reconheceu crianças e adolescentes como "sujeitos de direitos" foi a Constituição Federativa do Brasil, promulgada em 1988.

A Constituição reproduziu o movimento político responsável pela fabricação de "outra" sensibilidade ética em relação ao universo infanto-adolescente, ${ }^{2}$ servindo como parâmetro para pensar as diferentes governamentalidades sobre eles. Esse reconhecimento legal foi fruto do movimento que se articulou nas ruas e nas praças, desdobramento da Campanha Criança Constituinte, que, por sua vez, deu base ao Artigo 227 da Constituição de 1988, fazendo reconhecer esses agentes sociais como sujeitos de direitos.

A Campanha foi organizada por entidades e organismos governamentais que questionavam as legislações e as políticas vigentes e fez surgir, com base em articulação dos movimentos sociais e setores governamentais mais progressistas, o Estatuto da Criança e do Adolescente. Acredito que o Estatuto em si não representa um "avanço" ou um "progresso", mas um marco histórico na mudança de concepção sobre a legislação e a política voltadas para meninos e meninas, sem, no entanto, uma conquista vivenciada por agentes sociais que 
se organizaram de forma individual e coletiva para a institucionalização dos direitos humanos de meninas e meninos, fazendo modificar a forma de pensar a "arte de governar" crianças e adolescentes no Brasil. De acordo com Diogo Soares da Silveira,

A promulgação do Estatuto foi acompanhada pela emergência de um novo vocabulário conceitual, envolvendo instituição de novas categorias sociais como criança em situação de vulnerabilidade, jovem infrator e medida socioeducativa, entre outros. Esse movimento de concepção de novas categorias também resultou em um processo de reordenamento institucional que ainda se encontra em andamento e que visa reformular as políticas e instituições voltadas para as crianças e os adolescentes em todos os níveis governamentais, tendo como referência os princípios e diretrizes anunciados na nova legislação. (Silveira, 2015, p.63)

Esse processo contou com a participação das próprias crianças e dos adolescentes que, por meio do Movimento Nacional de Meninos e Meninas de Rua, ocuparam a Explanada dos Ministérios, na Capital Federal, em defesa do fim do Código de Menores. Foi no período da redemocratização que assistimos à atuação dos movimentos sociais, nos quais "novos protagonistas" entraram em cena e, com eles, a luta em defesa do "direito a ter direitos" (Miranda, 2015).

Contudo, ao realizar uma leitura crítica do Estatuto, é preciso entender o processo de sua produção com base no tempo histórico. Os novos estudos sociais da criança sinalizam que, mesmo representando um marco histórico da legislação pró-infância, o dispositivo carrega consigo uma ideia de "sujeito universal” fortemente marcado pela concepção liberal dos direitos humanos, que, por sua vez, busca universalizar a ideia de criança e adolescente. Segundo Schuch: "A imagem da 'criança universal' aparece com a internacionalização de sua atenção, personagem que passa a guiar as legislações e normativas internacionais, marcadamente liberais, embora a expansão dessa influência tenha se dado em um momento histórico de presença de uma ideologia modernista no Brasil" (Schuch, 2009, p.127).

Esse princípio universalista já estava presente na Convencional dos Direitos da Criança e do Adolescente, de 1989, que serviu como base para a produção do Estatuto. De acordo com Castro, 
Por mais que o direito positivo ocidental tenha recentemente manifestado a preocupação com a criança, vista como um sujeito de direitos, através da Convenção Internacional dos Direitos da Criança (1989), problematiza-se também sua racionalidade universalizante. Os 181 países signatários dessa Convenção se conformaram a uma visão de criança e de sociedade, passando por cima de situações culturais particulares que fazem da infância e dos valores a ela atribuídos algo diferente do que quer a visão dos países centrais. (Castro, 2002, p.51)

Com base nessa crítica, é preciso revisitar a própria história do Estatuto, buscando desconstruir imagens sacralizadas produzidas sobre ele. O dispositivo legal fabricado na década de 1990 não é o mesmo de hoje, e os próprios movimentos sociais buscam modificá-lo, haja vista as novas demandas políticas e mudanças nas relações de poder-saber que têm se desdobrado em outras governamentalidades sobre o público infanto-adolescente.

Costumo dizer que, se o Estatuto fosse escrito nos dias de hoje, seguramente poderia ser chamado de "Estatuto das Crianças e dos Adolescentes". Agora é necessário reconhecer as diferentes identidades infanto-adolescentes. Não há como reconhecer os sujeitos de direitos sem permitir que as diferentes identidades sejam promovidas.

É importante destacar os movimentos que promovem fissuras no próprio Estatuto, que buscam quebrar com a ideia de "infância universal". O primeiro movimento foi vivenciado no Conselho Nacional dos Direitos da Criança e do Adolescente (Conanda), que publicou, no ano de 2016, a Resolução 181, que estabelece os parâmetros para crianças e adolescentes de povos e comunidades tradicionais a partir do respeito à sociodiversidade. ${ }^{3}$ De acordo com a Resolução:

A aplicação da legislação pertinente à infância e à adolescência nas questões específicas que envolvam Crianças e Adolescentes oriundas de Povos e Comunidades Tradicionais deverá considerar as garantias jurídicas presentes na legislação específica dos Povos e Comunidades Tradicionais, assim como a autodeterminação, as culturas, os costumes, os valores, as formas de organização social, as línguas e as tradições. (Brasil, 2016)

Entendo a Resolução como uma forma de romper com a concepção universalista de infância. Esse documento foi produzido sobre uma concepção da 
infância no plural, processo marcado pelas tensões e disputas políticas que se desdobraram na promoção de uma perspectiva contra-hegemônica dos direitos humanos. De acordo com o sociólogo Boaventura de Souza Santos: “A busca de uma concepção contra-hegemônica dos direitos humanos deve começar por uma hermenêutica da suspeita em relação aos direitos humanos tal como são convencionalmente entendidos e defendidos, isto é, em relação às concepções dos direitos humanos mais diretamente vinculadas à matriz liberal e ocidental" (Santos, 2013, p.43).

Ainda nessa perspectiva, o segundo movimento provocou outra mudança significativa na forma de conceber o conceito de criança e de adolescente. Refere-se à Resolução 191, de 2017, que dispõe sobre a participação de adolescentes nos espaços de decisão política, mais notadamente no próprio Conselho Nacional do Direito da Criança e do Adolescente (Conanda). De acordo com o documento, o Conanda e os conselhos estaduais, distritais e municipais devem promover a participação cidadã de meninos e meninas nos espaços de decisão política, promovendo a democratização nesses lugares a partir do protagonismo desses "sujeitos de direitos".

As resoluções do Conanda possuem força normativa e vinculante, conforme estabelece o Artigo 59 da Constituição Federal. Por meio de tais resoluções, as políticas voltadas para o público infanto-adolescente passam a dialogar com as novas preocupações produzidas pelos movimentos sociais e pelos coletivos políticos organizados pelas crianças e adolescentes. Elas descortinam as novas formas de pensar as infâncias, refletindo diretamente em nosso cotidiano.

Penso que um conjunto de regulações normativas (Códigos, Leis, Resoluções) não se voltam apenas para redefinir os conteúdos estabelecidos, mas para repensar as relações socioculturais no mundo, na escola e na própria sala de aula. Também acredito que a Lei por si só não muda as diferentes realidades, para além da Lei devemos respeitar e valorizar a vida. Assim, como trabalhar os diferentes sujeitos nas aulas de História?

É preciso reconhecer as identidades culturais de crianças e adolescentes e, com base em suas complexidades, ter o cuidado respeitoso de não homogeneizar. A homogeneização nega as identidades nas suas especificidades e, negando a identidade, nega-se também o sujeito. ${ }^{4}$ 
Desse modo, a luta travada na década de 1980 para enfrentar a cultura menorista convive, nos dias de hoje, com a luta para romper com a ideia de "sujeito universal" ainda presente no Estatuto da Criança e do Adolescente. É possível afirmar que pensar a constituição da subjetivação das pessoas é voltar-se para as práticas produzidas nas relações de poder, na fabricação dos dispositivos que os reconhecem direito e que produzem normativas e regulações sobre suas práticas macro e microfísicas cotidianas.

Desse modo, é importante perceber os direitos de crianças e adolescentes para além do Estatuto e reconhecer a necessidade de que esse dispositivo também se modifique e dialogue com as novas formas de pensar as infâncias. Esse movimento anda em consonância com a ideia de que os direitos humanos também passam por constantes mudanças. Como afirmou a historiadora Lynn Hunt (2009, p.27), é preciso perceber que "os direitos permanecem sujeitos a discussão porque nossa percepção de quem tem direitos e do que são esses direitos muda constantemente". Afinal, reforça a pesquisadora, "a revolução dos direitos humanos é, por definição, contínua”.

O menorismo não foi abolido com o fim do Código de Menores e com o surgimento do Estatuto da Criança e do Adolescente, em 1990. Ele permanece nas práticas sociais que defendem, por exemplo, a Redução da Maioridade Penal; daqueles que, sob uma perspectiva punitivista, negam o direito ao adolescente de viver sua adolescência e fazem questão de perceber os problemas sociais que afetam diretamente os nossos meninos e meninas como um problema de polícia. Nesse sentido, tomando como ponto de partida um campo de tensão e de disputas, crianças e adolescentes também enfrentam tal processo de constituição do sujeito. E como diz Candiotto: "O mestre ou senhor de si não é somente aquele que deixou de ser parentalmente tutelado; ou que passou a ser imputável juridicamente pelos seus atos e suas consequências. Trata-se, antes, de alguém que está em luta permanente para empreender ações livres diante das recorrentes formas de tutela que procuram determinar suas escolhas e decisões" (Candiotto, 2016, p.34).

Dessa perspectiva, é possível defender a ideia de que crianças e adolescentes podem tornar-se "senhores de si". Nos diferentes mundos em que transitam, eles e elas podem apreender ações de liberdade para consigo e para com o mundo. Podem, a partir de seus universos particulares, encampar processos 
de lutas em defesa de seus direitos de viver suas infâncias e então se constituírem como sujeitos de direitos ou sujeitos à história.

Aprendi com Foucault (1995) que os processos de objetivação são acompanhados pelos processos de subjetivação, e que as leis, as doutrinas e os discursos institucionais, sob a lógica do Estado Moderno, fabricaram modos de subjetivações do indivíduo tendo em conta as relações de poder e saber. Aprendi também que, ao nos perguntarmos "como os seres humanos tornaram-se sujeitos?", nos engajamos em "lutas antiautoritárias", que nos levam ao questionamento: "quem somos nós?".

Ao pensar em como crianças e adolescentes tornaram-se sujeitos de direitos, faço-me engajar em uma luta antiautoritária. Luta contra a cultura menorista que insiste em não reconhecer a cidadania de meninos e meninas dentro e fora da escola; luta contra as pedagogias tradicionais que buscam produzir a "infância ideal" e o "aluno ideal".

É preciso reconhecer os diferentes sujeitos para que a tensão entre o processo de subjetivação se fortaleça frente às práticas de objetivação, como afirma Foucault. A partir da luta em defesa da infância, esses meninos e meninas que viviam em diferentes situações de vulnerabilidades deixaram de ser considerados "menores" e se tornaram "sujeitos de direitos".

Essa mudança desafiou e ainda hoje desafia as artes de "fazer" e de "viver" a educação, afetando diretamente a forma como praticamos os processos de aprendizagens, as didáticas e as formas de avaliações. Desse modo, qual o lugar desses meninos e meninas no processo de ensino-aprendizagem? Em que medida se reproduz o menorismo na sala de aula? Afinal, se construímos "outro" conceito de infância, isso implica a prática de "outra" maneira de pensar em como nos relacionamos com crianças e adolescentes. Mas o que esse processo tem a ver com as aulas de História?

\section{DiREITOS DAS CRIANÇAS E DOS ADOLESCENTES: DESAFios Para as aUlas de História}

Percebo a aula de História como um espaço estratégico para que crianças e adolescentes possam vivenciar a cultura dos direitos humanos. É por meio do saber histórico escolar que as pessoas podem cultivar a consciência de sua história, possibilitando uma melhor relação para consigo, com o mundo e com 
as outras pessoas. Assim, a sala de aula pode permitir que meninos e meninas conheçam o passado para melhor entender o presente, passo fundamental para que as pessoas se tornem sujeitos da história.

De acordo com as Diretrizes Curriculares da Educação Básica, o Ensino de História deve estar preocupado com a promoção da "consciência política e histórica". Ao estabelecer uma série de diretrizes baseadas nos princípios do "fortalecimento de identidades e de direitos", a primeira a ser elencada foi "a igualdade básica de pessoa humana como sujeito de direitos" (Brasil, 2013, p.484).

Para que os princípios da educação em direitos humanos presentes nas Diretrizes sejam vividos, é necessário (re)pensar o espaço sala de aula ainda marcado pela rigidez disciplinar e pela relação verticalizada. Segundo os estudos de Henry Giroux e Anthony Penna, é preciso pensar o conhecimento escolar e sua conexão com as relações sociais e a vida na sala de aula. Para esses pesquisadores, tal espaço exerce função importante, uma vez que "trabalhar em sala de aula significa aprender a viver em agrupamentos" (Giroux; Penna, 1997, p.61). E como esse debate pode contribuir com a discussão sobre a relação entre aula de História e os direitos da criança e dos adolescentes?

Geralmente, o debate sobre os direitos humanos de crianças e adolescentes chega à sala de aula por meio da leitura do Estatuto da Criança e do Adolescente, que vem sendo tratado como mais um dispositivo legal a estabelecer parâmetros ou diretrizes para o Ensino de História. O Estatuto se encontra presente nas próprias Diretrizes Curriculares da Educação Básica, na Base Nacional Comum, nos editais do Programa Nacional do Livro Didático (PNLD). Contudo, é importante saber como ele chega à aula de História, para além de fundamentar documentos ou de transversalizar conteúdos, saber como o sentimento de que esses meninos e meninas são sujeitos de direitos é vivenciado nas relações humanas construídas no espaço escolar.

Há três desafios centrais para os professores de História que se encontram abertos à possibilidade de vivenciar os direitos da criança e do adolescente em sua sala de aula. Buscando conexões com o que já foi debatido, tentarei provocar uma reflexão crítica em relação a esses desafios, compreendidos como desafios para o professor e a professora: 1) (re)pensar as concepções tradicionais do "ser criança" e do "ser adolescente"; 2) concebê-los como sujeitos de direitos; 3) reconhecer as diferentes infâncias. 
Sobre o primeiro desafio, percebo que ao (re)pensarmos as concepções socialmente construídas sobre crianças e adolescentes é fundamental "quebrar as imagens historicamente" construídas sobre eles e elas. A imagem dos "menores": do "menor carente", do "menor abandonado" ou da "infância inocente". De acordo com Lucia Rabello de Castro,

A infância universalizada nas práticas socioculturais que lhe deram um estatuto de inocência e fragilidade não seria, então, a meu ver, nada mais que uma narrativa, uma ficção por onde a racionalidade ocidental moderna construiu, através de marcos etários rígidos e universais, o acesso à "idade da razão", ou ainda, à plena cidadania, dentro de uma sociedade que se quis igualitária e livre. (Castro, 2002 p.51)

Para o pesquisador Miguel Arroyo é preciso "quebrar as imagens românticas das infâncias", percebendo que nossa "tendência fácil é trocar a imagem dócil por seu oposto, a "violência" ou reproduzir a imagem que "nossos sonhos docentes" produzem:

O desencanto é uma perda das imagens que provocam nossa docência, a educação e as escolas. Colocamos a pergunta: que olhares projetamos sobre os alunos? Com que imagens os representamos? Que imagens carregamos da infância, adolescência e juventude? Os(as) alunos(as) "que não são mais os mesmos" cabem nessas imagens? Não nos incomodam exatamente porque quebraram essas imagens? Vivenciar essas inseguranças pode ser positivamente amedrontador. (Arroyo, 2014, p.35)

Entre perguntas e afirmações, esse autor me levou a refletir que, para quebrar as imagens romantizadas de crianças e adolescentes, é necessário viver o desencanto da perda que, mesmo sendo uma experiência amedrontadora, torna-se positiva. O desencanto tem a ver com as imagens que preconcebemos ou reproduzimos da nossa própria infância. Contudo, é importante perceber que a criança e o adolescente de hoje não são os mesmos, logo, as infâncias não podem ser as mesmas.

Dessa perspectiva, é fundamental respeitar as trajetórias e os tempos desses meninos e meninas nos sentidos individuais e coletivos. Cada menino e cada menina tem a sua trajetória e seu tempo, mesmo fazendo parte de uma 
cultura infanto-adolescente. Essa nova forma de conceber as infâncias se reflete diretamente na forma como penso a didática, a avaliação e, principalmente, minha relação pessoal com crianças e adolescentes.

Penso que não há como garantir o respeito à dignidade humana desses agentes sociais sem efetivamente respeitá-los nas suas identidades geracionais, ou seja, é preciso respeitar o "ser criança” e o "ser adolescente". É preciso respeitar as formas como crianças e adolescentes veem o mundo e agem sobre ele, os modos como protestam e reivindicam e as expectativas que eles constroem sobre suas vidas. Daí a relevância de as aulas de história estarem abertas para promoção das identidades infanto-adolescentes, cabendo aos profissionais que lidam com o saber histórico escolar estarem comprometidos com o respeito à trajetória e ao tempo de cada estudante.

O segundo desafio para as aulas de História é reconhecer meninos e meninas como "sujeitos de direitos", promovendo a sua cidadania na sala de aula e, por conseguinte, na escola e para além dela. A aula de História pode ser um espaço de constituição da subjetivação dessas pessoas que estão na condição de estudante e como tal devem vivenciar a sala de aula de forma cidadã.

Ao reconhecer que são sujeitos de direitos, é importante reconhecer as pessoas que estão sendo acolhidas na sala de aula. As pessoas são crianças e adolescentes que pensam, sentem e dizem sobre os problemas vividos no cotidiano. Não são "adultos em miniatura" que enfrentam as adversidades da vida a partir das experiências acumuladas no decorrer dos anos. Pessoas que diariamente enfrentam os desafios de lidar os seus problemas sociais vividos em suas famílias ou as diferentes violências trazidas de suas comunidades.

Preciso ainda afirmar que não me refiro unicamente aos meninos e meninas das periferias ou das famílias pobres. É preciso perceber que crianças e adolescentes vivenciam as mais diferentes adversidades ou violação de direitos, independentemente de sua condição econômica.

Reconhecer crianças e adolescentes como sujeitos de direitos já representa um importante passo para efetivação dos direitos humanos e para o questionamento das práticas menoristas. Para isso é fundamental desconstruir a ideia de que estamos educando para "preparação da vida adulta" ou para o "adulto de amanhã”. Esse sentimento é eminentemente adultocêntrico e interfere diretamente no comprometimento das relações afetivas e educacionais, uma vez que tal prática não reconhece a identidade cultural infanto-adolescente. 
Enquanto sujeitos, crianças e adolescentes representam um presente contínuo e merecem ser respeitados a partir de sua trajetória infantil. Afinal, reconhecer os sujeitos é reconhecer as suas "vozes". Mas como possibilitar que crianças e adolescentes falem nas aulas de História?

Esse exercício não significa apenas reformular a disposição das carteiras e colocá-las em modo circular. Antes de permitir que meninos e meninas falem, é necessário estar aberto à escuta ética e respeitosa. Ou seja, a criança e o adolescente falam/verbalizam do jeito deles, sentem a partir do universo deles, produzem horizontes de expectativas baseados em suas trajetórias e constroem modos de intervenção e participação sobre as relações construídas na sala de aula.

Essa questão implica diretamente o reconhecimento da cidadania de crianças e adolescentes e a responsabilidade política e ética de professores e professoras. Educar para cidadania e para democracia. De acordo com Selva Guimarães, "cabe à História e às ciências humanas que compõem a base comum curricular assumir seu lugar e seu papel formativo nos processos de ensino e aprendizagem, educando as novas gerações ancoradas nos princípios e nas diretrizes da educação republicana e democrática em nosso país: igualdade, solidariedade, liberdade, pluralismo e respeito" (Guimarães, 2016, p.75).

Acredito que educar para cidadania é proporcionar que a própria cidadania seja vivenciada na sala de aula. Desse modo, é de fundamental importância construir avaliações de como vem sendo oportunizada e garantida a participação de crianças e adolescentes nas aulas de História. A avaliação permitirá perceber se "igualdade, solidariedade, liberdade, pluralismo e respeito" estão sendo promovidos na sala de aula.

O terceiro e último desafio refere-se ao reconhecimento das diferentes formas de viver as infâncias. Romper com a lógica universalizante é fundamental para construção de uma sociedade que promova as diferenças. Entender a infância no plural é um desafio que seguramente deve ser enfrentado para que possamos construir "outro" projeto de sociedade.

É nesse momento que a aula de História tem um espaço de respeito junto aos direitos humanos e sua efetividade. Ao analisar a relação entre o saber histórico escolar e os direitos humanos, a pesquisadora Cinthia Monteiro de Araujo considera a aula de História como um espaço privilegiado para o debate dos direitos humanos, afirmando que 
A relação entre o ensino de História e os direitos humanos passa pelo empoderamento, pela formação de uma memória histórica que combata a cultura da impunidade e proporcione o reconhecimento das diferenças, pela formação de sujeitos autônomos conscientes de seus direitos e deveres, e capaz de agir no coletivo buscando o bem comum. (Araujo, 2013, p.72)

A aula de História é um espaço onde as diferentes infâncias podem ser reconhecidas e promovidas. Trabalhar os conteúdos das trajetórias de vida e dos grupos sociais, motivando os estudantes a se reconhecerem na história, trazendo suas vivências construídas na família e na comunidade, possibilitando que meninos e meninas conheçam o passado, pensem o presente e formulem "uma questão para o futuro". Como afirmou o historiador Manoel Salgado Guimarães, formular uma questão para o futuro é "acreditar na vida e na possibilidade de transformação pela ação humana, sem, no entanto, acreditar que o futuro nos aguarda com a casa pronta" (Guimarães, 2007, p.39).

Os três desafios se coadunam e não podem ser vividos separadamente. Também acredito que, com base nas aulas de História, meninos e meninas possam construir outra forma de intervir no próprio espaço escolar, nas famílias e nas suas comunidades. Podem interferir na gestão escolar e nas decisões domésticas, podem se organizar politicamente e construir intervenções nos grupos sociais que circulam, participar de forma mais cidadã nas decisões fora e dentro da sala de aula.

Essa aula de História pode contribuir para outra cultura escolar, haja vista que a escola real muitas vezes não está preparada para reconhecer crianças e adolescentes como sujeitos de direitos, uma vez que a cultura menorista ainda permeia muitas das suas práticas pedagógicas. Como afirma Marchi, a escola como "o dispositivo criado para encerrar a infância tanto do ponto de vista topológico ou corpóreo, quanto do ponto de vista das categorias que a pedagogia e a psicologia educacional elaboraram para construí-la" (Marchi, 2009, p.233).

Para além da programação escolar estabelecida no seu calendário, os conteúdos curriculares e as ações pedagógicas que fazem parte da cultura escolar, professores/as de História devem lidar com as diferentes realidades vividas por crianças e adolescentes. Aponto como problema fundamental construir o sentido do ensino de História para a vida desses meninos e meninas. 
Esses três desafios me fizeram pensar a aula de História como espaço de luta e que, a partir dela, é possível construir outra forma de não só pensar a própria sala de aula e a escola, mas também apontar para outro projeto de sociedade. Um projeto no qual crianças e adolescentes se constituam como sujeitos e não como projeto dos interesses dos adultos, contribuindo para que a cultura menorista seja enfrentada na sala de aula e para além dela.

\section{CONSIDERAÇÕES FINAIS}

Neste trabalho, a aula de História assumiu um sentido, foi concebida como o espaço estratégico de viver os direitos de crianças e adolescentes. Viver o direito de pensar sobre as questões e os problemas sociais enfrentados no cotidiano, de dizer e se expressar de forma cidadã e de sentir as tristezas e as alegrias que o mundo lhes oferece. Pode parecer utópico, mas penso que são as utopias que alimentam a luta e, como diz Foucault, conceber o ser humano como sujeito é acreditar na luta antiautoritária.

Nesse sentido, questionar a cultura menorista é uma luta antiautoritária. O menorismo é autoritário, uma vez que ele nega o sujeito e estabelece que meninos e meninas sejam objeto dos interesses adultos. $\mathrm{O}$ autoritarismo no Brasil contemporâneo encontra-se na defesa da Redução da Maioridade Penal e de outras pautas conservadoras comprometedoras dos direitos humanos conquistados. Autoritarismo maior é não permitir que as próprias crianças e adolescentes não tenham consciência histórica dos problemas sociais que norteiam seu cotidiano e que estão diretamente relacionados às suas formas de viver a vida.

Os desafios apresentados neste artigo devem ser compartilhados com os diferentes profissionais da educação que atuam na escola. Penso no compromisso com os direitos da criança e do adolescente como um projeto coletivo que os próprios meninos e meninas devem assumir.

É nas aulas de História que meninos e meninas podem ser mobilizados nos sentidos intelectual, ético e político para pensar, sentir e dizer sobre esses problemas e de outros que façam parte do seu cotidiano. Percebo as aulas de História como o espaço da "luta antiautoritária". A História vivida na sala de aula tem sentido e pode ter vários sentidos. Acredito que um desses sentidos é não negar o mundo que vivemos. 
É possível e necessário que o Ensino de História seja promovido "para e pelos direitos humanos", cultivando o respeito e a valorização das diferentes culturas infantis, fora e dentro da sala de aula. Promover o pensar, o sentir e o dizer é fundamental para que meninos e meninas vivenciem o direito de ter direito. Reconhecer que meninos e meninas são "sujeitos" é promover o direito de viver as diferentes infâncias.

\section{REFERÊNCIAS}

ARAUJO, Cinthia M. de. Alianças entre o PNEDH e o ensino de história: concepções docentes sobre as relações entre educação e direitos humanos. Educação, Porto Alegre (impresso), v.36, n.1, p.67-73, jan./abr. 2013.

ARIÈS, Philippe. História social da criança e da família. 2.ed. Rio de Janeiro: LTC, 1981.

ARROYO, Miguel. Imagens quebradas: trajetórias e tempos dos alunos e mestres. Petrópolis: Vozes, 2014.

BRASIL. Conselho Nacional dos Direitos da Criança e do Adolescente - Conanda. Resolução 181. Brasília, 2016.

. Conselho Nacional dos Direitos da Criança e do Adolescente - Conanda. Resolução 191. Brasília, 2017.

. Estatuto da Criança e do Adolescente. Lei 8.069/1990. Brasília, 1990.

. Ministério da Educação. Diretrizes Curriculares Nacionais Gerais da Educação Básica. Brasília, 2013.

CANDIOTTO, Cesar. Sujeito, agnóstica e seus desdobramentos políticos no pensamento de Michel Foucault. In: NALI, Marcos; VARGAS, Sonia Regina (Org.) Michel Foucault: desdobramentos. Belo Horizonte: Autêntica, 2016. p.29-39.

CASTRO, Lucia R. de. A infância e seus destinos no contemporâneo. Psicologia em Revista, Belo Horizonte, v.8, n.11, p.47-58, jun. 2002.

FOUCAULT, Michel. O sujeito e o poder. In: DREYFUS, Hubert; RABINOW, Paul. Michel Foucault, uma trajetória filosófica: para além do estruturalismo e da hermenêutica. Rio de Janeiro: Forense Universitária, 1995. p.231-249.

GIROUX, Henry; PENNA, Anthony. Educação Social em sala de aula: a dinâmica do currículo oculto. In: GIROUX, Henry. Os professores como intelectuais: rumo a uma pedagogia crítica da aprendizagem. São Paulo: Artmed, 1997. p.55-77.

GUIMARÃES, Manoel Luiz S. O presente do passado: as ates de Clio em tempos de memória. In: ABREU, Martha; GONTIJO, Rebeca; SOIHET, Rachel (Org.) Cultura 
política e leituras do passado: historiografia e ensino de história. Rio de Janeiro: Civilização Brasileira, 2007. p.25-41.

GUIMARÃES, Selva. Ensinar história: formar cidadãos no Brasil democrático. In: . Ensino de história e cidadania. Campinas: Papirus, 2016. p.75-105.

HUNT, Lynn. A invenção dos Direitos Humanos: uma história. São Paulo: Companhia das Letras, 2009.

MARCHI, Rita de Cássia. As teorias da socialização e o novo paradigma para os estudos sociais da infância. Educação \& Realidade, v.34, n.1, p.227-246, jan.-abr. 2009.

MIRANDA, Humberto da S. Entre ruas e praças: a trajetória do Movimento Nacional de Meninos e Meninas de Rua no Recife (1980). In: SIMPÓSIO NACIONAL DE HISTÓRIA, 28., 2015, Florianópolis. Anais... Florianópolis: Anpuh, 2015.

Nos tempos das Febems: memórias de infâncias perdidas (Pernambuco/1964-1985). Tese (Doutorado em História) - Programa de Pós-Graduação em História, Universidade Federal de Pernambuco (UFPE). Recife, 2014.

PAES, Paulo Cesar D. Redução da Maioridade Penal, sofrimento e criminalização da pobreza. In: PAES, Paulo Cesar D.; ADIMARI, Maria F.; COSTA, Ricardo P. (Org.) Socioeducação e intersetorialidade. Campo Grande: Ed. UFMS, 2015. p.85-95.

SANTOS, Boaventura de S. Direitos humanos, democracia e desenvolvimento. São Paulo: Cortez, 2013.

SCHUCH, Patrice. Práticas de Justiça: antropologia dos modos de governo da infância e da juventude no contexto pós-ECA. Porto Alegre: Ed. UFRGS, 2009.

SILVEIRA, Diogo S. da. Governamentalidades, saberes e políticas públicas na área de Direitos Humanos de Criança e do Adolescente. In: REZENDE, Heraldo de (Org.) Michel Foucault: o governo da infância. Belo Horizonte: Autêntica, 2015.

VIANNA, Adriana de R. O mal que se adivinha: polícia e menoridade no Rio de Janeiro, 1910-1920. Rio de Janeiro: Arquivo Nacional, 1999.

\section{NOTAS}

${ }^{1}$ Além da Redução da Maioridade Penal, que "coloca como causa problema da criminalidade no Brasil os/as adolescentes de 16 a 18 anos que cometem ato infracional", outras propostas conservadoras tramitam na Câmara Federal ou no Senado brasileiro em Projetos de Leis ou Projetos de Emendas Constitucionais, apresentados por parlamentares. As propostas foram apresentadas por deputados ou senadores oriundos de partidos conservadores. A Redução da Maioridade Penal, oficializada como Projeto de Emenda Constitucional 171, é de autoria do deputado Benedito Domingos, do Partido Progressista do Distrito Federal, no ano de 1993, e objetiva alterar a redação do art. 228 da Constituição Federal, modificando a imputabilidade penal do maior de 16 anos, e já se encontra na Comissão de 
Constituição, Justiça e Cidadania do Senado como PEC 33/2012. Já a PEC da Vida, de autoria do senador Magno Malta, do Espírito Santo, propõe alterar a Constituição Federal para acrescentar no art. 5\%, "da inviolabilidade do direito à vida, desde a concepção", mesmo em casos nos quais a mãe sofreu violência. Por fim, a o Estatuto da Família/PL 6583/13, apresentado pelo deputado Anderson Ferreira, do Partido da República de Pernambuco, que concebe a família apenas de uniões formadas por homens e mulheres. Sobre a Redução da Maioridade Penal ver: PAES, 2015.

${ }^{2}$ Neste artigo, devo utilizar a terminologia "cultura infanto-adolescente" ou "público infanto-adolescente" para me referir às questões relacionadas às crianças e aos adolescentes, haja vista que vou me debruçar sobre a análise de pessoas de até 18 anos de idade. Percorrendo as produções de pesquisas realizadas no campo do Ensino de História, percebi que esse desafio se desdobra na própria forma de conceituar a criança e o adolescente. Encontrei trabalhos sobre adolescentes identificando-os como jovens, por exemplo. É importante repensar o compromisso com a infância para que por meio das pesquisas no campo do Ensino de História possamos contribuir com as mudanças na sala de aula. Ser jovem é diferente de ser adolescente, assim como ser adolescente é diferente de ser criança.

${ }^{3}$ De acordo com a Resolução, é necessário respeitar os direitos de crianças e adolescentes de "povos indígenas, comunidades quilombolas, povos e comunidades de terreiro/povos e comunidades de matriz africana, povos ciganos, pescadores artesanais, extrativistas, extrativistas costeiros e marinhos, caiçaras, faxinalenses, benzedeiros, ilhéus, raizeiros, geraizeiros, caatingueiros, vazanteiros, veredeiros, apanhadores de flores sempre-vivas, pantaneiros, morroquianos, povo pomerano, catadores de mangaba, quebradeiras de coco babaçu, retireiros do Araguaia, comunidades de fundos e fechos de pasto, ribeirinhos, cipozeiros, andirobeiros, caboclos, entre outros" (BRASIL, 2016).

Artigo recebido em 25 de fevereiro de 2018. Aprovado em 27 de agosto de 2018. 